\title{
Hubungan antara Minum Teh dengan Glukosa Darah Sewaktu pada Mahasiswa Fakultas Kedokteran Universitas Islam Al-Azhar
}

\author{
Artha Budi Duarsa*, Muhammad Hidayatullah ** \\ Fakultas Kedokteran Universitas Islam Al-azhar \\ Email: arthaduarsa@unizar.ac.id
}

\begin{abstract}
ABSTRAK
Penyakit Tidak Menular (PTM) adalah penyebab kematian terbanyak di Indonesia. Menurut Kementerian Kesehatan RI (2014), proporsi diabetes mellitus pada penduduk usia $\geq 15$ tahun sekitar 5,7\% pada tahun 2007, dan meningkat menjadi 6,9\% di tahun 2013. Provinsi NTB khususnya kota Mataram, sesuai dengan data Riskesdas (2013) yang menunjukan jumlah penderita diabetes mellitus terus meningkat dari tahun ke tahun mengikuti gaya hidup dan tingkat obesitas yang semakin tinggi. Penelitian ini dilakukan untuk mengetahui hubungan antara minum teh dengan glukosa darah sewaktu. Metode penelitian yang digunakan adalah pre eksperimental dengan rancangan one group pretest posttest. Populasi dalam penelitian ini adalah mahasiswa preklinik Fakultas Kedokteran Universitas Islam Al-Azhar. Setelah dilakukan perhitungan didapatkan jumlah sampel sebesar 35 responden, penentuan sampel menggunakan teknik purposive sampling. Analisis data dengan SPSS 23 menggunakan uji-t berpasangan. Hasil penelitian menunjukkan bahwa terdapat hubungan yang bermakna antara minum teh dengan glukosa darah sewaktu pada mahasiswa Fakultas Kedokteran Universitas Islam Al-Azhar.
\end{abstract}

\section{Kata kunci: Minum teh, glukosa darah sewaktu, diabetes mellitus}

\section{PENDAHULUAN}

Penyakit Tidak Menular (PTM) adalah penyebab kematian terbanyak di Indonesia. Keadaan dimana penyakit menular masih merupakan masalah kesehatan yang penting dan dalam waktu yang bersamaan morbiditas dan mortalitas PTM makin meningkat sehingga menjadi beban ganda dalam pembangunan bidang kesehatan di Indonesia, salah satunya ialah diabetes mellitus (Riskesdas, 2013). Diabetes Mellitus merupakan suatu kumpulan gejala yang timbul pada seseorang yang disebabkan karena peningkatan kadar glukosa darah akibat penurunan sekresi insulin yang progresif yang dilatarbelakangi oleh resistensi insulin (Soegondo et al., 2009). Menurut Kementerian Kesehatan RI (2014), proporsi diabetes mellitus pada penduduk usia $\geq 15$ tahun sekitar $5,7 \%$ pada tahun 2007. Sedangkan pada tahun 2013, didapatkan proporsi diabetes mellitus sekitar 6,9\%. Sementara di Provinsi Nusa Tenggara Barat sendiri khususnya kota Mataram, prevalensi diabetes mellitus sebesar 1,8\%. Sesuai dengan data Riskesdas (2013) yang menunjukan jumlah penderita diabetes mellitus terus meningkat dari tahun ke tahun mengikuti gaya hidup dan tingkat obesitas yang semakin tinggi, akibatnya biaya pelayanan kesehatan akan menjadi semakin besar dan semakin tinggi bila disertai komplikasi dengan penyakit lain (Kemenkes RI, 2014).

$$
\text { World Health Organization }
$$

(WHO) telah memberikan beberapa rekomendasi untuk mencegah diabetes 
mellitus yaitu berolahraga, memelihara indeks massa tubuh yang optimal dan juga menjaga diet makanan (WHO, 2003). Selain itu, menurut Hyun dan Jae Taek (2013) teh juga dapat membantu menurunkan kadar glukosa darah pada tikus diabetik (Hyun dan Jae Taek, 2013).

Sebagian besar orang mulai menyadari bahwa teh merupakan minuman kesehatan sehingga mendorong banyak pihak untuk mengembangkan minuman teh, mulai dari produk-produk berbasis teh hingga membuat produk teh siap minum dalam kemasan botol. Kandungan pada teh yang membuat minuman ini menjadi berkhasiat adalah kandungan polifenol yang bermanfaat bagi kesehatan tubuh (Rohdiana et al., 2012, 2013).

Penelitian-penelitian sebelumnya juga menunjukan bahwa teh memiliki aktivitas anti diabetes. Salah satunya ekstrak air panas teh hitam juga menunjukan kemampuan menurunkan kadar glukosa darah pada tikus yang diinduksi streptozotocin

(Broadhurst, 2000 dalam Holidah et al., 2016). Selain itu, penelitian eksperimental yang dilakukan oleh Jocom (2015) di Laboratorium Farmakologi Fakultas Kedokteran Universitas Sam Ratulangi juga menunjukan adanya penurunan kadar gula darah pada tikus setelah pemberian teh oolong. Bertolak belakang dengan hasil penelitian yang dilakukan oleh Kuo, et al (2005) di Taiwan yang menunjukan bahwa teh hijau tidak menurunkan kadar glukosa darah akan tetapi dapat mengurangi resiko diabetes mellitus (Kuo et al, 2005).

Akibat kurangnya data serta penelitian yang langsung dilakukan pada manusia mengenai pengaruh minum teh terhadap kadar glukosa darah, maka terlebih dahulu dilakukan penelitian pendahuluan untuk meningkatkan kepercayaan asumsi. Pada penelitian pendahuluan digunakan sampel sebesar 7 responden. Penelitian ini dilakukan dengan pengukuran pada subjek penelitian sebelum diberikan perlakuan minum teh dan melakukan pengukuran kembali sesudah diberi perlakuan. Rerata kadar glukosa darah responden sebelum perlakuan sebesar 105,85 mg/dL. Sedangkan rerata kadar glukosa darah setelah perlakuan sebesar 87,42 mg/dL. Hasil menunjukan adanya penurunan kadar glukosa darah setelah diberikan perlakuan minum teh yaitu dengan rerata sebesar $18,42 \mathrm{mg} / \mathrm{dL}$. Berdasarkan pada uraian di atas, maka perlu dilakukan penelitian lebih lanjut untuk mengetahui hubungan antara minum teh dengan glukosa darah. 
METODOLOGI PENELITIAN

Penelitian ini menggunakan metode pre-eksperimental. Sedangkan desain atau rancangan penelitian menggunakan one group pretest posttest design.

\section{Cara Kerja Pemeriksaan Glukosa}

\section{Darah Sewaktu}

Peneliti meminta persetujuan subjek penelitian dengan mengisi dan menandatangani formulir informed consent; perangkat glukometer yaitu uji strip, lancet, dan alkohol pada, mencuci tangan dengan sabun dan memakai handscoon untuk mencegah infeksi;membersihkan daerah yang akan ditusuk (jari ketiga atau jari keempat) dengan alkohol pad, diamkan sebentar sampai alkohol kering;menusuk jari dengan lancet, lalu ambil satu tetes darah untuk diperiksa, tunggu beberapa saat sampai hasil keluar; mencatat hasil.

\section{HASIL DAN PEMBAHASAN}

\section{Hasil Penelitian}

\section{Karakteristik Dasar Sampel}

Diagram 1. menunjukkan karakteristik sampel berdasarkan umur subjek. Didapatkan subjek terbanyak dengan hasil berturut-turut yaitu pada umur 20 tahun sebanyak 8 subjek (22,9\%), 22 tahun sebanyak 7 subjek (20\%), 19 tahun sebanyak 6 subjek $(17,1 \%), 21$ tahun sebanyak 5 subjek $(14,3), 23$ tahun sebanyak 5 subjek
$(14,3 \%), \quad 18$ tahun sebanyak 3 subjek $(8,6 \%)$ dan 24 tahun sebanyak 1 subjek $(2,9 \%)$. Sementara karakteristik responden berdasarkan jenis kelamin didapatkan subjek laki-laki sebanyak 11 orang $(31,4 \%)$ dan perempuan sebanyak 24 orang $(68,6 \%)$.

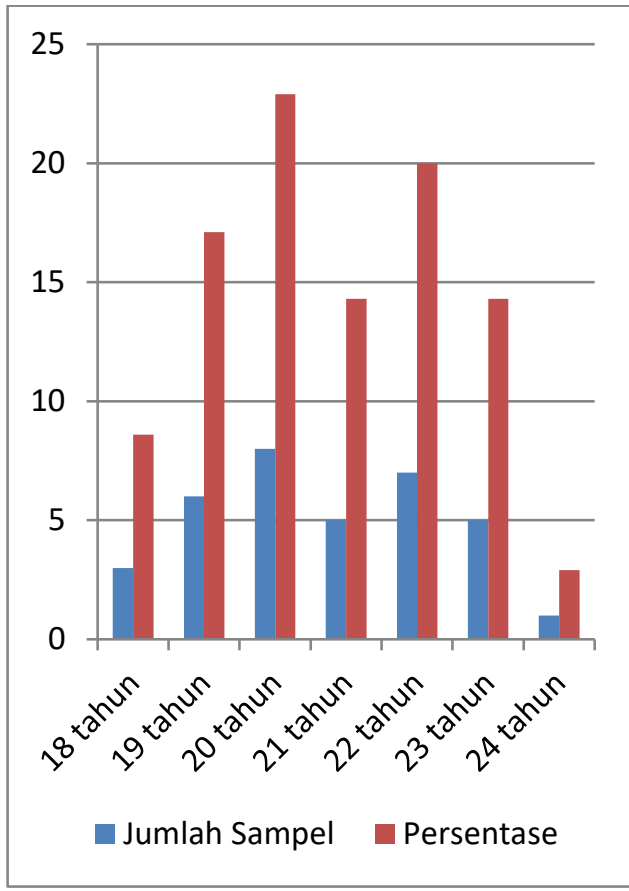

\section{Diagram 1. Karakteristik sampel} berdasarkan umur mahasiswa Fakultas Kedokteran Universitas Islam Al Azhar

Tabel 1. menunjukan rerata kadar glukosa darah sewaktu 35 responden sebelum minum teh. Didapatkan rerata sebesar 91,49 mg/dL dengan kadar terendah sebesar $66 \mathrm{mg} / \mathrm{dL}$ dan kadar tertinggi sebesar $139 \mathrm{mg} / \mathrm{dL}$. 
Tabel 1. Rerata interval kadar

Glukosa Darah sewaktu

sebelum minum teh pada

mahasiswa Fakultas

Kedokteran Universitas

Islam Al-Azhar

\begin{tabular}{|c|c|c|c|c|}
\hline No. & $\begin{array}{c}\text { GDS } \\
\text { sebelum } \\
\text { minum } \\
\text { teh } \\
(\mathrm{mg} / \mathrm{dL})\end{array}$ & $\begin{array}{c}\text { Jumlah } \\
\text { Sampe } \\
1\end{array}$ & $\begin{array}{c}\text { Persentase } \\
\quad(\%)\end{array}$ & $\begin{array}{l}\text { Rerata } \\
(\mathrm{mg} / \mathrm{dL} \\
\text { ) }\end{array}$ \\
\hline 1 & 66 & 1 & 2,9 & \multirow{23}{*}{91,49} \\
\hline 2 & 72 & 3 & 8,6 & \\
\hline 3 & 74 & 2 & 5,7 & \\
\hline 4 & 76 & 2 & 5,7 & \\
\hline 5 & 77 & 1 & 2,9 & \\
\hline 6 & 78 & 1 & 2,9 & \\
\hline 7 & 79 & 1 & 2,9 & \\
\hline 8 & 81 & 3 & 8,6 & \\
\hline 9 & 83 & 4 & 11,4 & \\
\hline 10 & 85 & 2 & 5,7 & \\
\hline 11 & 87 & 1 & 2,9 & \\
\hline 12 & 93 & 1 & 2,9 & \\
\hline 13 & 95 & 2 & 5,7 & \\
\hline 14 & 99 & 1 & 2,9 & \\
\hline 15 & 102 & 1 & 2,9 & \\
\hline 16 & 109 & 1 & 2,9 & \\
\hline 17 & 110 & 2 & 5,7 & \\
\hline 18 & 114 & 1 & 2,9 & \\
\hline 19 & 115 & 1 & 2,9 & \\
\hline 20 & 116 & 1 & 2,9 & \\
\hline 21 & 124 & 1 & 2,9 & \\
\hline 22 & 133 & 1 & 2,9 & \\
\hline 23 & 139 & 1 & 2,9 & \\
\hline \multicolumn{2}{|c|}{ Jumlah } & 35 & 100 & 91,49 \\
\hline
\end{tabular}

Tabel 2 menunjukan rerata kadar glukosa darah sewaktu 35 responden sesudah minum teh. Didapatkan rerata sebesar 78,57 mg/dL dengan kadar terendah sebesar $51 \mathrm{mg} / \mathrm{dL}$ dan kadar tertinggi sebesar $102 \mathrm{mg} / \mathrm{dL}$.
Gambar 4.3 Rerata kadar glukosa darah sewaktu sebelum dan sesudah perlakuan (Data Primer, 2018)

Tabel 2. Rerata interval kadar glukosa darah sewaktu sesudah minum teh pada mahasiswa Kedokteran Universitas Islam Al-Azhar

\begin{tabular}{ccccl}
\hline GDS & & & \\
No. & $\begin{array}{c}\text { Resudah } \\
\text { minum } \\
\text { teh } \\
(\mathrm{mg} / \mathrm{dL})\end{array}$ & $\begin{array}{c}\text { Jumlah } \\
\text { Sampe }\end{array}$ & $\begin{array}{c}\text { Persentase } \\
(\%)\end{array}$ & $\begin{array}{l}\text { Rerata } \\
(\mathrm{mg} / \mathrm{dL}\end{array}$ \\
\hline
\end{tabular}

\begin{tabular}{ccccc}
\hline & & 1 & 2,9 & \\
1 & 51 & 1 & 2,9 & \\
3 & 64 & 2 & 5,7 & \\
4 & 69 & 6 & 17,1 & \\
5 & 70 & 2 & 5,7 & \\
6 & 74 & 1 & 2,9 & \\
7 & 75 & 1 & 2,9 & \\
8 & 77 & 4 & 11,4 & \\
9 & 78 & 1 & 2,9 & \\
10 & 79 & 2 & 5,7 & \\
11 & 81 & 1 & 2,9 & 78,57 \\
12 & 82 & 2 & 5,7 & \\
13 & 83 & 2 & 5,7 & \\
14 & 85 & 3 & 8,6 & \\
15 & 87 & 1 & 2,9 & \\
16 & 90 & 1 & 2,9 & \\
17 & 95 & 2 & 5,7 & \\
18 & 99 & 1 & 2,9 & \\
19 & 102 & 1 & 2,9 & \\
\hline Jumlah & & 35 & 100 & 78,57 \\
\hline
\end{tabular}

Tabel 3 menunjukan karakteristik sampel dari 35 subjek berdasarkan penurunan kadar glukosa darah sewaktu sesudah minum teh. Didapatkan 26 subjek $(74,3 \%)$ mengalami penurunan kadar glukosa darah sewaktu. 
Sedangkan 9 subjek tidak mengalami penurunan kadar glukosa darah sewaktu.

Tabel 3. Karakteristik sampel

Berdasarkan penurunan

kadar glukosa darah

sewaktu pada mahasiswa

Fakultas Kedokteran

Universitas Islam Al- Azhar

\begin{tabular}{llll}
\hline No. & Penurunan & $\begin{array}{l}\text { Jumlah } \\
\text { Sampel }\end{array}$ & $\begin{array}{l}\text { Persentase } \\
(\%)\end{array}$ \\
\hline 1 & Ya & 26 & 74,3 \\
2 & Tidak & 9 & 25,7 \\
\hline \multirow{2}{*}{ Jumlah } & 35 & 100
\end{tabular}

Hasil Analisis Bivariat

Tabel 4. Uji normalitas selisih kadar glukosa darah sewaktu sebelum dan sesudah minum teh

\begin{tabular}{lcc}
\hline & Sig. & Distribusi \\
\hline $\begin{array}{l}\text { Selisih } \\
\text { kadar } \\
\text { glukosa }\end{array}$ & & \\
darah & & \\
sewaktu & 0,02 & Normal \\
sebelum & & \\
dan & & \\
sesudah & & \\
minum teh & & \\
\hline
\end{tabular}

Tabel 4 menunjukkan hasil uji normalitas data. Uji normalitas yang digunakan adalah Shapiro-Wilk karena sampel kurang dari 50. Uji normalitas dilakukan untuk mengetahui keadaan data berdistribusi normal atau tidak. Pada uji normalitas data yang menggunakan Shapiro-Wilk, diperoleh selisih kadar glukosa darah sewaktu sebelum dan sesudah minum teh terdistribusi normal $(\mathrm{p}>0,01)$.

Tabel 5. Rerata peningkatan glukosa darah sewaktu

\begin{tabular}{|c|c|c|c|}
\hline ariabel & $\begin{array}{l}\text { Rerata } \\
(\mathrm{mg} / \mathrm{dL})\end{array}$ & Value & I $99 \%$ \\
\hline $\begin{array}{l}\text { Kadar } \\
\text { glukosa } \\
\text { darah } \\
\text { sebelum } \\
\text { perlakuan } \\
\text { Kadar } \\
\text { glukosa } \\
\text { darah } \\
\text { sesudah } \\
\text { perlakuan }\end{array}$ & 8,57 & ,000 & $\begin{array}{l}\text { ( } 955- \\
20,873\end{array}$ \\
\hline
\end{tabular}

Tabel 5 menunjukkan penurunan glukosa darah sewaktu sesudah minum teh. Berdasarkan uji statistik menggunakan SPSS 23 dengan uji-t berpasangan diperoleh nilai $\mathrm{p}$ sebesar 0,000 yang mana ini menunjukan kemaknaan yang signifikan dimana nilai $\mathrm{p}<0,01$. Dari hasil output uji $\mathrm{t}$ berpasangan dengan nilai $0,000<0,01$ maka H0 ditolak dan Ha diterima yang berarti terdapat hubungan yang signifikan anatara minum teh dengan glukosa darah sewaktu.

Nilai interval kepercayaan (IK) dinyatakan bersama tingkat kepercayaan yang telah ditetapkan yaitu 99\%. Pada pengukuran glukosa darah sewaktu responden ditemukan IK 99\% 4,95520,873 mg/dL, ini berarti bila dilakukan penelitian berulang kali dengan teknik 
sampling yang sama pada populasi tersebut, akan didapatkan kepercayaan sebesar $99 \%$ bahwa rerata dari penelitian-penelitian itu akan terletak dalam interval 4,955 sampai 20,873 $\mathrm{mg} / \mathrm{dL}$ dan nilai sesungguhnya yang diluar nilai ekstrem hanya $1 \%$ dari kemungkinan. Rentang IK menjadi lebar diakibatkan tingkat kepercayaan yang tinggi yakni 99\%. Hal ini karena penelitian dilakukan pada manusia yang menuntut untuk menggunakan tingkat kepercayaan yang tinggi. Untuk mempersempit rentang IK, dapat dilakukan dengan memperbesar sampel penelitian. Namun beberapa keterbatasan seperti dana, tenaga, dan waktu, peneliti menggunakan besar sampel minimal sesuai perhitungan. Sehingga kemungkinan terambil hanya subjek dari kelompok-kelompok ekstrem rendah atau tinggi saja.

\section{Pembahasan}

Penelitian ini dilakukan di Fakultas Kedokteran Universitas Islam Al-Azhar, Kelurahan Turide Timur, Kota Mataram, Nusa Tenggara Barat, dilaksanakan selama satu hari pada tanggal 26 Januari 2018. Penelitian ini menggunakan metode pre eksperimental. Sedangkan desain atau rancangan penelitian yang digunakan ialah one group pretest posttest design. Penelitian dilakukan dengan mengukur subjek penelitian (pre-test) sebelum diadakannya perlakuan (treatment) dan melakukan pengukuran kembali setelah diberi perlakuan (posttest). Sampel diambil dengan menggunakan teknik purposive sampling. Berdasarkan perhitungan, didapatkan sampel minimal sebesar 35 responden.

Sebelum melakukan penelitian, subjek penelitian telah diberikan penjelasan terkait tindakan yang akan dilakukan dan mengisi lembar persetujuan (informed consent). Selain itu, telah dijelaskan pula untuk tidak berpuasa, tidak mengkonsumsi obatobatan, tidak beraktivitas fisik lebih dari 30 menit, serta tidak mengkonsumsi teh dan kopi.

Pada saat penelitian, ditanyakan kembali kepada subjek penelitian apakah telah mengikuti semua penjelasan yang telah diberikan. Hal ini dilakukan untuk mengontrol variabelvariabel lain agar didapatkan hasil penelitian yang sahih. Selanjutnya dilakukan pengukuran glukosa darah sewaktu sebelum dan sesudah minum teh. Setelah semua data terkumpul, dilakukan analisis data dengan uji statistik yakni analisis univariat untuk mendeskripsikan masing-masing variabel dan analisis bivariat untuk mengetahui adanya hubungan antara variabel bebas dengan variabel terikat. Sedangkan untuk mengetahui pengaruh 
tersebut bermakna atau tidak, analisis statistik yang digunakan ialah uji-t berpasangan.

Berdasarkan hasil penelitian, didapatkan rerata glukosa darah sewaktu sebelum minum teh sebesar 91,49 $\mathrm{mg} / \mathrm{dL}$. Sedangkan rerata glukosa darah sewaktu sesudah minum teh sebesar 78,57 mg/dL. Rerata selisih kadar glukosa darah sewaktu sebelum dan sesudah minum teh ialah sebesar 16 $\mathrm{mg} / \mathrm{dL}$. Hasil uji statistik menggunakan uji-t berpasangan menunjukkan $p$-value sebesar 0,000. Hal ini menunjukkan pula bahwa $p$-value $<0,01$ sehingga $\mathrm{H}_{0}$ ditolak yang berarti terdapat hubungan yang signifikan antara minum teh dengan glukosa darah sewaktu. Sedangkan nilai interval kepercayaan (IK) pada pengukuran glukosa darah sewaktu 35 responden ditemukan IK 99\% 4,955-20,873 $\mathrm{mg} / \mathrm{dL}$, ini berarti bila dilakukan penelitian berulang kali dengan teknik sampling yang sama pada populasi tersebut, akan didapatkan kepercayaan sebesar $99 \%$ bahwa rerata dari penelitian-penelitian itu akan terletak dalam interval 4,955 sampai 20,873 $\mathrm{mg} / \mathrm{dL}$ dan nilai sesungguhnya yang diluar nilai ekstrem hanya $1 \%$ dari kemungkinan. Rentang IK menjadi lebar diakibatkan tingkat kepercayaan yang tinggi yakni 99\%. Hal ini karena penelitian dilakukan pada manusia yang menuntut untuk menggunakan tingkat kepercayaan yang tinggi. Untuk mempersempit rentang IK, dapat dilakukan dengan memperbesar sampel penelitian. Namun beberapa keterbatasan seperti dana, tenaga, dan waktu, peneliti menggunakan besar sampel minimal sesuai perhitungan. Sehingga kemungkinan terambil hanya subjek dari kelompok-kelompok ekstrem rendah atau tinggi saja.

Hasil penelitian ini sesuai dengan penelitian eksperimental yang dilakukan oleh Jocom (2015) di Laboratorium Farmakologi Fakultas Kedokteran Universitas Sam Ratulangi juga menunjukan adanya penurunan kadar gula darah pada tikus setelah pemberian teh oolong serta penelitian.

Penurunan kadar glukosa darah terjadi karena adanya hormon insulin yang menurunkan kadar glukosa darah. Insulin meningkatkan pemakaian karbohidrat sebagai sumber energi, namun menekan pemakaian lemak (Guyton dan Hall, 2007; Sherwood, 2011). Penelitian yang dilakukan oleh Anderson dan Polansky (2002) menyebutkan bahwa teh hijau, teh oolong, dan teh hitam secara signifikan meningkatkan aktivitas insulin secara in vitro. Hal ini sejalan dengan hasil penelitian karena dari 35 responden terdapat 26 orang $(74,3 \%)$ mengalami penurunan kadar glukosa darah sewaktu. 
Sedangkan peningkatan kadar glukosa darah disebabkan oleh hormon glukagon sebagai respon tubuh untuk menjaga konsentrasi glukosa darah agar tetap dalam keadaan normal. Glukagon memiliki efek pemecahan glikogen hepar (glikogenolisis) dan meningkatkan proses glukoneogenesis di hepar (Guyton dan Hall, 2007; Murray et al, 2016). Hal ini sejalan dengan hasil penelitian karena dari 35 responden, terdapat 9 orang $(25,7 \%)$ mengalami peningkatan kadar glukosa darah yang kemungkinan disebabkan oleh proses glikogenolisis dan glukonegenesis sebagai respon dari penurunan glukosa darah yang drastis akibat minum teh.

\section{KESIMPULAN}

Berdasarkan hasil penelitian yang telah dilakukan bahwa aktifitas minum teh dapat menurunkan kadar glukosa darah sewaktu pada mahasiswa Fakultas Kedokteran Universitas Islam Al-Azhar dan diperkuat dengan hasil uji hipotesis bahwa terdapat hubungan yang signifikan antara minum teh dengan glukosa darah sewaktu

\section{DAFTAR PUSTAKA}

American Diabetes Association. 2014. Diagnosing Diabetes and Learning about Prediabetes. http://www.diabetes.org/diabe tes-basics/diagnosis/. Diakses pada tanggal 1 september 2017
Anderson, R.A, Polansky, MM. 2002. Tea Enhaces Insulin Activity. Journal of Agricultural and Food Chemistry. 50:71827186

Babu P.V, Sabitha K.E, Shyamaladevi C.S. 2006. Green Tea Extract Impedes Dyslipidemia and Development of Cardiac Dysfunction in Streptozotocin Diabetic Rats. Clinical and Experimental Pharmacology and Physiology 33. 1184-1189

Balittri, JT. 2013. Kandungan Senyawa Kimia pada Daun Teh (Camellia Sinensis). Warta Penelitian dan Pengembangan Tanaman Industri, Volume 19 Nomor 3.

Bernard, A.S., Kerure, S.B. 2013. Glucose Handling during Menstrual Cycle. International Journal of Reproduction, Obstetrics and Gynecology.

Champe, PC et al. 2010. Biokimia Ulasan Bergambar Edisi 3. Jakarta: EGC.

Dorlan, Newman W.A. 2011. Kamus Kedokteran Dorlan Edisi 28. Jakarta: EGC.

Fernandez-Caceres, P.M.J., et al. 2001. Differentiation of Tea (Camellia Sinensis) Varieties and Their Geographical Origin According to Their Metal Content. J. Agric. Food Chem.

Guyton dan Hall. 2014. Buku Ajar Fisiologi Kedokteran Edisi 12. Singapore: Saunders Elsevier.

Guyton, Arthur C. 2007. Human Physiology and Mechanisms of Disease. Dalam : Andrianto, petrus. Fisiologi Manusia dan Mekanisme Penyakit. EGC. Jakarta.

Heroniaty. 2012. Sintesis Senyawa Dimer Katekin dari Ekstrak Teh Hijau dengan Menggunakan Katalis Enzim Peroksidase dari Kulit Bawang Bombay (Allium Cepa L.). Tesis di Fakultas Matematika dan Ilmu Pengetahuan Alam. Depok 
Holidah, D., Christianty, F.M. 2016. Uji Aktivitas Antidiabetes Ekstrak Teh Hitam, Teh Oolong, dan Teh Hijau Secara In Vivo. Prosiding Seminar Nasional Current Challenges in Drug Use and Development. Tantangan Terkini Perkembangan Obat dan Aplikasi Klinis.

Hyun Minkim dan Jae Taek Kim. 2013. The Effect of Green Tea on Obesity and Tipe 2 Diabetes. Diabetes Metab. J. 37 (3): 173175

Jocom, E.G., et al. 2015. Pengaruh Pemberian Teh Cina dan Teh Melati Terhadap Penurunan Kadar Gula Darah pada Tikus Wistar. Jurnal Kedokteran Komunitas dan Tropik Volume III Nomor 3.

Katzung, B. G. 2007. Farmakologi Dasar dan Klinik Edisi 10. Jakarta: EGC.

Kementerian Kesehatan RI. 2013. Diabetes Mellitus Penyebab Kematian Nomor 6 di Dunia: Kemenkes Tawarkan Solusi CERDIK Melalui Posbidu. http://www.depkes.go.id/article/v iew/2383/diabetes-melituspenyebab-kematian-nomor-6-didunia-kemenkes-tawarkan-solusicerdik-melalui-posbindu.html.

Diakses pada tanggal 10 september 2017

Kementerian Kesehatan RI. 2013. Riset Kesehatan Dasar (Riskesdas) Tahun 2013. Jakarta: Badan Penelitian dan Pengembangan Kesehatan Kementerian Kesehatan RI.

Kementerian Kesehatan RI. 2014. Situasi dan Analisis Diabetes. Jakarta: Pusat Data dan Informasi Kementerian Kesehatan RI.

Kementerian Pertanian RI. 2016. Outlook Teh Komoditas Pertanian Subsektor Perkebunan. Jakarta: Pusat Data dan Sistem Informasi Pertanian Sekretariat Jenderal Kementerian Pertanian.
Kuo, K.L., M.S. Weng, C.T. Chiang, Y.J. Tsa, S.Y.L. Shiau, and J.K. Lin. 2005. Comparative Studies on The Hypolipidemic and Growth Supressive Effects of Oolong, Black, Pu-erh, and Green Tea Leaves in Rats. J. Agric. Food Chem.

Lemon, P., Burke, K. 2002. Medical Surgical Nursing: Critical Thinking in Client Care. Jakarta

Murray, R.K., Granner, D.K., Rodwell, V.W. 2009. Biokimia Harper. Jakarta: EGC

Notoatmodjo Soekidjo. (2010). Metodologi Penelitian Kesehatan. Jakarta: EGC Rineka Cipta.

Oktavia, Nova. 2015. Sistematika Penulisan Karya Ilmiah Edisi 1. Yogyakarta: EGC.

Price Sylvia A, Wilson, Lorraine M. 2005. Patofisiologi Konsep Klinis Proses-Proses Penyakit Volume 2. Jakarta: EGC.

Prodia. 2015. Tata Cara Puasa Untuk Pemeriksaan Glukosa Puasa dan 2 Jam PP. Mataram: Prodia

Putri, D.D., et al. 2015. Pengaruh Suhu dan Waktu Ekstraksi terhadap Kadar Kafein dalam Teh Hitam. Jurnal Sains dan Seni ITS Vol. 4, No. 2.

Rohdiana, D. 2009. Teh Hitam dan Antioksidan. Indonesia: Pusat Penelitian Teh dan Kina Gambung.

Rohdiana, D., et al. 2012. Uji Antidiabetes Ekstrak Etanol Teh Hijau pada Tikus Putih. Jurnal Penelitian Teh dan Kina, Vol. 15 No. 1.

Rohdiana, D., et al. 2013. Aktivitas penangkapan radikal bebas DPPH (1,1-Diphenyl-2Picrylhydrazyl) oleh Teh Putih Berdasarkan Suhu dan Lama Penyeduhan. Jurnal Penelitian Teh dan Kina, Vol. 16 No. 1.

Rumahorbo, H. 1999. Asuhan Keperawatan Klien dengan Gangguan Sistem Endokrin. Jakarta: EGC. 
https://books.google.co.id/books ?id=L-

GQDTpN2AIC\&pg=PA116\&dq $=$ Patofisiologi+hipoglikemia\&hl =id\&sa=X\&ved=0ahUKEwivos Thv6zUAhUMv5QKHb_DCYU Q6AEIJzAD\#v=onepage \&q=pat ofisiologi\%20hipoglikemia \& $\mathrm{f}=\mathrm{f}$ alse (Diakses pada tanggal 7 september 2017).

Sandhar, H.K., B. Kumar, S. Prashes, P. Tiwari, M. Salhan, P. Sharma. 2011. A Review of Phytochemistry and Pharmacology of Flavonoids. Internationale Pharmaceutica Scienca Jan-Mar 2011 Vol 1 Issue 1.

Sastroasmoro, S., Ismael, S. 2008. Dasar-Dasar Metodologi Penelitian Klinis. Jakarta: CV. Sagung Seto.

Sherwood, Lauralee. 2011. Fisiologi Manusia Dari Sel ke Sistem. Jakarta: EGC.

Soegondo, S., Soewondo, P., Subekti, I. 2009. Penatalaksanaan Diabetes Melitus Terpadu. Jakarta: FKUI.

Sohle, J., Knott A., Holtzmann U., Siegner R., Gronniger E., Schepky A., Gallinat S., Wenck H., Stab F, and Winnefeld M. 2009. White Tea Extract Induces Lipolytic Activity and Inhibits Adipogenesis in Human Subcutaneous (pre)-Adipocuyes. Nutrition \& Metabolism.

Sudoyo AW, Bambang S, Idrus A. 2009. Buku Ajar Ilmu Penyakit Dalam Jilid III Edisi V. Jakarta: Interna Publishing.

Sugiyono. 2013. Metode Penelitian Kuantitati, Kualitatif, dan R\&D. Bandung: Alfabeta, CV.

Sumarny, R et al. 2012. Pengaruh Penambahan Seduhan Teh Hijau [Camelia Sinensis (Linn) Kunze] Terhadap Aktivitas Antioksidan Sari Buah Apel (Pyrus Mallus L.). Jurnal Sains dan Teknologi Farmasi, Vol.17, No. 1, Halaman 80-83.
Sunarto dan Surjono, A. 1997. Interval Kepercayaan Dalam Kemaknaan Klinis. Berkala Ilmu Kedokteran, Vol. 9, No. 3, Halaman 145-151

World Health Organization. 2003. WHO Technical Report Series: DIET, NUTRITION, AND THE OF CHRONIC DISEASES. Jenewa: WHO Publication. 